This is a self-archived - parallel published version of this article in the publication archive of the University of Vaasa. It might differ from the original.

\title{
How to Support Real-time Quantitative Big Data by More Future Orientated Qualitative Data for Understanding Everyday Innovative Businesses?
}

Author(s): Heimo, Teppo; Tilabi, Sara; Takala, Josu

Title: How to Support Real-time Quantitative Big Data by More Future Orientated Qualitative Data for Understanding Everyday Innovative Businesses?

Year: $\quad 2020$

Version: Author accepted manuscript

Copyright (C)2020 Taylor \& Francis. This is an Accepted Manuscript of an article published by Taylor \& Francis in Management in the Era of Big Data: Issues and Challenges on 15 June 2020, available online: https://www.taylorfrancis.com/chapters/edit/10.1201/978100305729 $1-17 /$

Please cite the original version:

Heimo, T., Tilabi, S. \& Takala, J. (2020). How to Support Real-time Quantitative Big Data by More Future Orientated Qualitative Data for Understanding Everyday Innovative Businesses? In Paliszkiewicz, J. (ed.): Management in the Era of Big Data: Issues and Challenges, 201-216. Boca Raton: CRC Press, Taylor \& Francis Group. https://www.taylorfrancis.com/chapters/edit/10.1201/9781003057291$17 /$ 
Chapter 15 - How to Support Real-time Quantitative Big Data by More Future-Orientated Qualitative Data for Understanding Everyday Innovative Businesses

Teppo Heimo, Sara Tilabi, and Josu Takala

University of Vaasa

\subsection{Introduction}

In today's world, we are generating data more than ever, i.e., data from social media, GPS signals, transaction records, digital images, scanners, sensors, etc. Innovation has played a significant role in producing all this data and it will play a dominant role in managing it. Big Data is an incentive factor for innovation. In more detail, when the size of the data becomes bigger than a certain limit, innovation process starts in order to store, organize, analyze, share, and use it in a meaningful way (Gobble, 2013). Not only Big Data is considered as a frontier for innovation, but also it promotes productivity and stimulates the competition considering its potential to create new business opportunities and revenues. It is estimated that Big Data would improve more than half of existing business and further billions of dollars of new business in the coming decades (Manyika, Chui, Brown, Bughin, Dobbs, Roxburgh, \& Byers, 2011). For example, Alyass, Turcotte, and Meyre (2015) studied how Big Data supports personalized medicine, and Dasgupta (2013) investigated the role of Big Data in helping farmers to adopt climate changes or to identify issues with a racing car in Formula 1 com- petition. Besides, there are studies showing how Big Data could be monetized by implementing the right choice of business strategy (Najjar \& Kettinger, 2013). To sum up, Big Data causes a revolution in the way we live, work, and think (Mayer- Schönberger \& Cukier, 2013). We observed this transformation within the past few years through the successful implementation of technological innovations like Uber and WeChat (Yang, Huang, Li, Liu, \& Hu, 2017).

As the application of Big Data is increasing, innovators are raising the questions associated with the challenges of Big Data to offer better quality services and products or to decrease the cost. As data is a great source of innovation, existing business is leveraging it to simplify the process, increasing efficiencies and to improve customer services. But innovation itself is a data-intensive activity, and organization, which considers it serious, produces a lot of data from ideas to lab test and documentation which could be analyzed and taken into account in further step of innovation process. In this regard, data generally and Big Data specifically have a major impact on driving and reshaping innovation process (Gobble, 2013). The prominent tool for the use of Big Data in companies is the Balanced Scorecard (BSC) (Vanani \& Kheiri, 2018). 
This research focuses on decision-making process regarding innovation and ultimately could facilitate innovation strategy. The results of this research show how the analytical model can quantitatively evaluate the state of companies' innovation strategy by using data derived from the company. Regarding the importance of data and its role in stimulating and reshaping innovation process, the results of this research work could have a significant practical implementation toward innovation strategy. The rest of this chapter is organized as follows: first theoretical background and research gap are presented. Then, the method section comes, and afterward empirical part is presented. And the final part is discussion and conclusion.

\subsection{Theoretical Background}

\subsubsection{Innovation}

Although the definition of innovation varies slightly in different existing scientific literature, there is agreement about its aim: creating tangible value by implementing sustainable solution to fulfill customer needs (Dziallas \& Blind, 2019; Racherla, Huang, \& Liu, 2016). The decision about innovation strategy is among the most fundamental strategic decision for every firm because of its inevitable role in helping the company to enter new markets, increase its share in the existing market, and sustain its competitive advantage (Gunday, Ulusoy, Kilic, \& Alpkan, 2011). This emphasis on innovation is due to intensifying the competition in both the global and domestic markets generated by rapid changes in technology (Bower \& Christensen, 1995). Market studies show that a company that innovates more is more capable to sustain its competitive position in global market (Cegarra-Navarro, Reverte, Gómez-Melero, \& Wensley, 2016). Therefore, innovation constitutes a inseparable part of firm business strategies. There are different reasons behind that, for example, the need to offer new products or improved ones, the need to improve efficiencies and productivity, and the need to perform better in some critical market (Karlsson \& Tavassoli, 2016). Innovation process could be classified into three different segments: front-end innovation (FEI), i.e., first and most important phase of innovation before the development and the commercialization process takes place, new product development (NPD) where the actual development of the innovation happens, and commercialization stage (Cegarra-Navarro et al., 2016; Mohan, Voss, \& Jiménez, 2017).

Innovation strategy could be categorized into two main classes: open and closed innovation

processes. Closed innovation is related to those companies that are mostly internally focused 
(Chesbrough, 2003a). In other words, in closed innovation model, company uses its own internal process in research and development (R\&D) process (Chesbrough, 2003b). On the other hand, in open innovation (OI) model, the inflows and outflows of traditional closed innovation process change. This results in two different innovation models: inside-out and outside- in innovation models or inbound and outbound models, respectively (Bogers, Chesbrough, \& Moedas, 2018). In outside-in Ol strategy, company chooses to integrate external knowledge into its internal innovation process by different means like supplier integration or customer involvement (Ahn, Ju, Moon, Minshall, Probert, Sohn, \& Mortara, 2016). Implementing inside-out innovation model helps the company to compensate its lack in internal resources and capabilities. On the other hand, in the inside-out model, company implements process to allow other companies to use its ideas and innovations in their business strategy and core operations (Gassmann \& Enkel, 2004). There is another OI model which is coupled Ol strategy in which the process of innovation from exploration, creation, and commercialization is done in cooperation with one or several external collaborators. In fact, this model is the integration of outside-in and inside-out models (Cheng \& Huizingh, 2014).

\subsection{Research Gap}

Innovation strategy could be considered based on company's resources and capabilities. Since resources of the firm are valuable, rare, inimitable, and substitutable (VRIN), they are the target of in-sourcing and out-licensing in corporate-level strategic issues, e.g., mergers and acquisitions (M\&A) and joint ventures. This pro- vides an opportunity for firms to apply external knowledge which is embedded in their overall strategy (Brem, Nylund, \& Hitchen, 2017). Studies show that technologically motivated M\&As encourages innovation in general. In detail, innovation efficiency increases where the technologies are complementary between the merged entities while it decreases in case of substitution of technologies (Colombo \& Garrone, 2006). This shows that OI strategy, i.e., using external source of knowledge for innovation is in line with M\&As and supports innovation process ultimately (Brem et al., 2017). Previous studies investigate the Ol impact from various perspectives, i.e., in terms of new units of analysis, small and medium enterprises (SMEs), non-profit organizations (NGOs), and different companies in low- and high-tech industry sector (Bogers et al., 2018). However, there is a need for studies that investigate the subject quantitatively. Therefore, this study is an attempt toward quantitative modeling of innovation process considering sustainable competitive advantages and tries to answer the following research questions: 
1. How can Big Data help companies to maintain their competitive advantage in today's turbulence business environment?

2. What are the strengths that Big Data brings to the discourse on innovation analytics?

3. Can the state of innovation be quantitatively analyzed using data extracted from the company?

\subsection{Method}

\subsubsection{Analytical Hierarchy Process}

"The Analytic Hierarchy Process (AHP) method is a multi-attribute decision instrument that allows considering quantitative, qualitative measures and making tradeoffs" (Wind \& Saaty, 1980; Pecchia, Bath, Pendleton, \& Bracale, 2011).

This method is based on pairwise comparison and is conducted in two stages: first respondents are given two different criteria regarding the object and they should choose which of them is more important. In the second step, the respondents should weight the chosen criterion from 1 to 9 . If the respondents choose one, it means both criteria are equal. The questionnaire for this study consisted of six pairwise questions of the four different main attributes. The main attributes are shown in Figure 15.1.

\begin{tabular}{|r|l|l|l|l|l|l|l|l|l|l|l|l|l|l|l|l|l|l|}
\hline & 9 & 8 & 7 & 6 & 5 & 4 & 3 & 2 & 1 & 2 & 3 & 4 & 5 & 6 & 7 & 8 & 9 & \\
\hline Knowledge & & & & & & & & & & & & & & & & & & Technology \\
\hline Knowledge & & & & & & & & & & & & & & & & & & Development \\
\hline Knowledge & & & & & & & & & & & & & & & & & Co-operation \\
\hline Technology & & & & & & & & & & & & & & & & & Development \\
\hline Technology & & & & & & & & & & & & & & & & & Co-operation \\
\hline Development & & & & & & & & & & & & & & & & & & Co-operation \\
\hline
\end{tabular}

Figure 15.1. Pairwise comparison of the main criteria. (Own research based on Heimo, 2019.)

When calculating the AHP, inconsistency ratio (ICR) should be taken into con- sideration. ICR shows how logically respondents answered the questionnaire. As an example, if respondents answered $A>B$ and $B>C$, then this statement should be $A>C$. If the respondents answered $C>A$, then its answer is not inconsistent. The ICR $<0.3$ is acceptable in most of the studies, but ICR $<0.1$ is preferred. 


\subsubsection{Innovation Strategy Index}

Derived from manufacture strategy index (MSI), we define innovation strategy index (ISI). MSI is calculated by assigning the attribute in AHP questionnaire as a component of RAL model, i.e., quality, time, cost, and flexibility and transfers the results to Miles and Snow business strategy type (Daft, Murphy, \& Willmott, 2010), i.e., prospector, analyzer, defender, and reactor. RAL is the abbreviation of Responsiveness, Agility, and Leanness and connects quality, time, cost, and flexibility as the main factors, which connects business performance to Miles and Snow typology. Once the share of quality, cost, flexibility, and time is calculated, the next step is to normalize the values. After normalization, a specific formula is used to calculate MSI indices (Ranta \& Takala, 2007). We follow the same steps to calculate ISI (Figure 15.2).
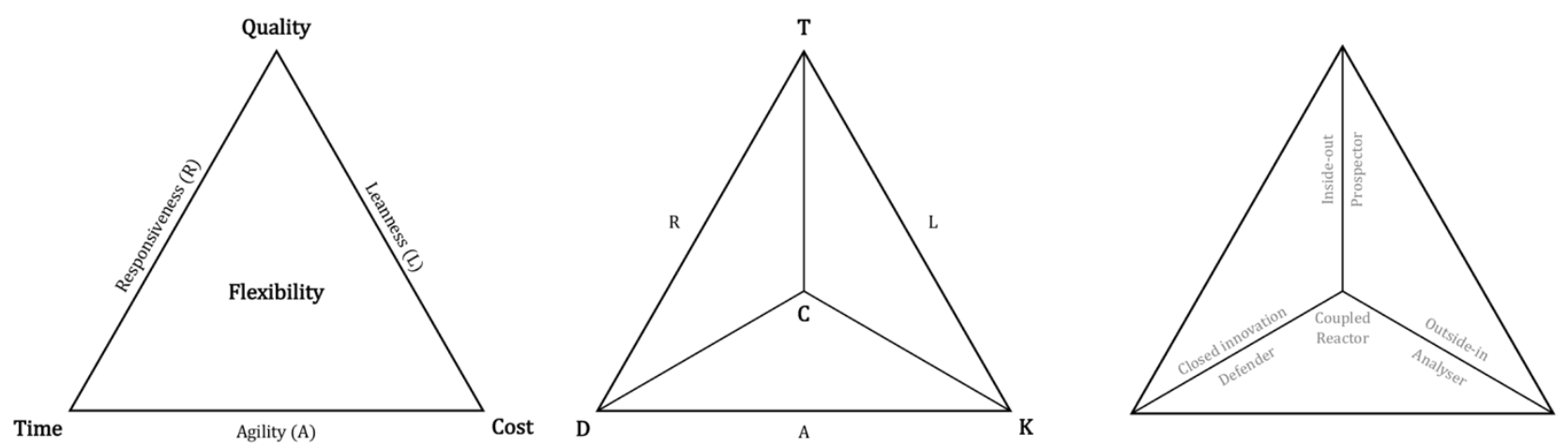

Figure 15.2. The demonstration RAL model, MSI, and ISI triangles. (Own research based on Ranta \& Takala, 2007; Heimo, 2019.)

In order to calculate ISI, we use the information obtained from AHP questionnaire comparing technology $(T)$, knowledge (K), development (D), and co-operation (C) factor. The ISI could be presented in the following equation:

$I S I=f_{I S I}(T, K, D, C)$

The next step is to normalize the component using the following formulas:

$$
\begin{aligned}
& T^{\prime}=\frac{T}{T+K+D} \\
& K^{\prime}=\frac{K}{T+K+D}
\end{aligned}
$$


$D^{\prime}=\frac{D}{T+K+D}$

$C^{\prime}=\frac{C}{T+K+D+C}$

Having normalized the component ISI are calculated as follow:

$\operatorname{InO}=\emptyset \sim 1-\left(1-T \%^{\frac{1}{3}}\right)(1-0.9 \times D \%)(1-0.9 \times K \%) \times C \% \frac{1}{3}$

$O u I=\gamma \sim 1-1(1-C \%) \times[A B S[(0.95 \times D \%-0.285) \times(0.95 \times K \%-0.285)]]^{3}$

$C I=\emptyset \sim 1-\left(1-K \%^{\frac{1}{3}}\right)(1-0.9 \times D \%)(1-0.9 \times T \%) C \% \%^{\frac{1}{3}}$

CO $=\frac{1}{2}($ Inside - out + closed innovation $)$

In the equations above the InO stands for inside-out, Oul for outside-in, $\mathrm{Cl}$ for closed innovation strategy, and $C O$ for coupled strategy in innovation strategy.

\subsubsection{Weak Market Test}

Here, the weak market test (WMT) is used to validate the results of the study since it is the first attempt to quantitatively model the innovation strategy of the case companies with this model. Conducting WMT means to show the results of the study to a responsible person in the company and ask his/her opinion about the constructed model and obtained results.

\subsection{Empirical Research}

This research was done using AHP method to gather data, which was at later stage converted to information by ISI method. The research attributes for the AHP method was determined based on the four most important main criteria in terms of closed innovation and OI. The initial research of OI was used as a theoretical frame- work for this study. Furthermore, the method for ISI follows the method developed by Takala, Shylina, Forss, and Malmi (2013) for operations strategy environment, 
which has been validated and verified to work in several studies (Liu \& Takala, 2009). In this study, the WMT was performed in a form of interviews with the case companies and used to validate the results obtained with the methods and models described earlier.

\subsection{Sample and Analysis}

The research consisted of two case companies operating in biotechnology and in vitro diagnostics (IVD) industries. The companies were SMEs and large multinational enterprise (LMNE), which has a subsidiary doing sales and marketing, $R \& D$, and production operations in Finland. The answers were collected from individuals operating in the top management of these companies.

\subsubsection{Case Company 1}

Based on the ISI model, the past timeframe innovation strategy type of the case company 1 (CC1) were closed innovation and outside-in Ol strategy type in the future timeframe as the individual values for different innovation types were highest in these strategy types and significantly above the average (AVG) values of other innovation strategies (Table 15.1). The order of the innovation strategy types for the past timeframe was closed innovation>coupled>inside-out>outside-in, and outside-in > inside-out $>$ coupled $>$ closed innovation for the future timeframe, respectively.

Table 15.1. Innovation Strategy Type of the Case Companies 1 and 2.

\begin{tabular}{|l|l|l|l|l|}
\hline & \multicolumn{2}{|c|}{ Case Company 1 } & \multicolumn{2}{c|}{ Case Company 2 } \\
\hline & Past & Future & Past & Future \\
\hline Inside-out & 0.9293 & 0.0301 & 0.9411 & 0.9592 \\
\hline Outside-in & 0.8473 & 0.9564 & 0.9010 & 0.8923 \\
\hline Closed Innovation & 0.9612 & 0.8955 & 0.9159 & 0.9324 \\
\hline Coupled & 0.9453 & 0.9128 & 0.9285 & 0.9458 \\
\hline AVG & 0.9208 & 0.9237 & 0.9216 & 0.9324 \\
\hline SD & 0.0507 & 0.0260 & 0.0172 & 0.0289 \\
\hline CV-\% & $5.50 \%$ & $2.81 \%$ & $1.86 \%$ & $3.10 \%$ \\
\hline Area & 1.0804 & 1.1167 & 1.0978 & 1.1182 \\
\hline ICR & 0.031 & 0.004 & 0.156 & 0.111 \\
\hline
\end{tabular}


The standard deviation (SD) of the innovation strategy types was above 0.015 , which were the predetermined threshold used in this study, and implies that there is sufficient variation between different innovation strategy types in the past time- frame. The coefficient of variation (CV-\%) of $5.50 \%$ further supports this fact. In the future timeframe, the SD of the innovation strategy types was also significantly above 0.015 , which also supports that there was sufficient variation between the innovation strategy types in the future timeframe as well. The CV-\% in the case of the future timeframe was $2.81 \%$, which is lower compared to the past timeframe but still elevated to point out that there is one innovation strategy type that protrudes from the other innovation strategy types. The ISI model results correlated with the priority weight results in both time- frames in the case of CC1. In the past timeframe, the highest values of the ISI and the priority weight models were the closed innovation strategy, and in the future timeframe, the highest values were in the outside-in OI strategy (Figure 15.3). The order of the innovation strategy models was the same in the ISI and priority weight models at both the past and the future timeframe. The total innovation potential based on the triangle area in the past timeframe was 1.0804 and 1.1167 in the future timeframe, respectively. From the $\Delta \mathrm{A}$, it is possible to determine that the total innovation potential is estimated to grow $3.35 \%$ from the past innovation experience to the future innovation expectation. In the following figures, the I represents inside-out Ol strategy, the O represents outside-in Ol strategy, and the Ci represents the closed innovation strategy.
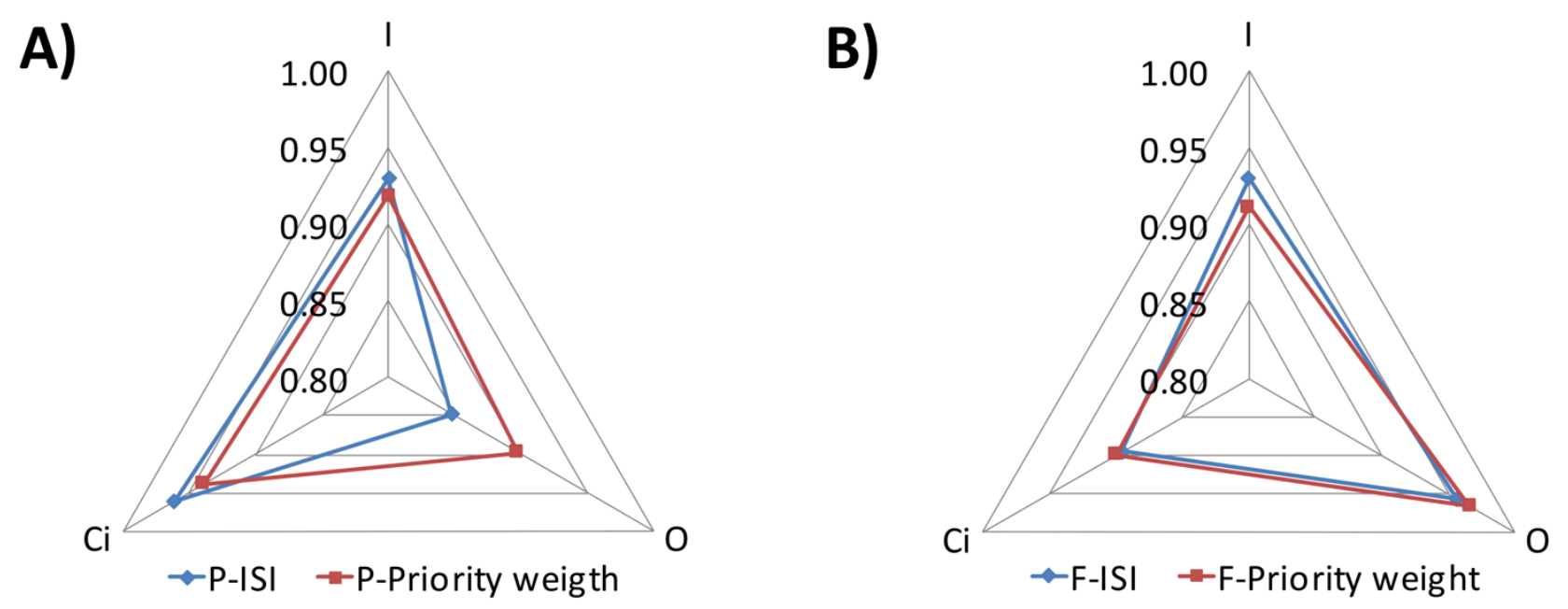

Figure 15.3. Innovation strategy index and priority weight comparison in CC1. RAL model (a) in the past timeframe and (b) in the future timeframe. (Own research.) 
According to the WMT, the empirical experience of the company's innovation strategy for the past timeframe has been closed innovation strategy supported by the fact that the innovation resources within the company have been largely assigned to its own R\&D. Accordingly, the expectations for the future timeframe innovation strategy type of the company are outside-in Ol strategy because of their ambition to seek in-organic growth from external technologies and innovations (Figure 15.4a). The company also incorporates inside-out innovation type in the past and the future timeframe as well. However, this innovation strategy type is not considered as important as the closed innovation strategy in the past timeframe nor the outside-in Ol strategy in the future timeframe. Based on the WMT, the experience of the past and the expectations of the future are well in line with the past and the future timeframe ISI model results.

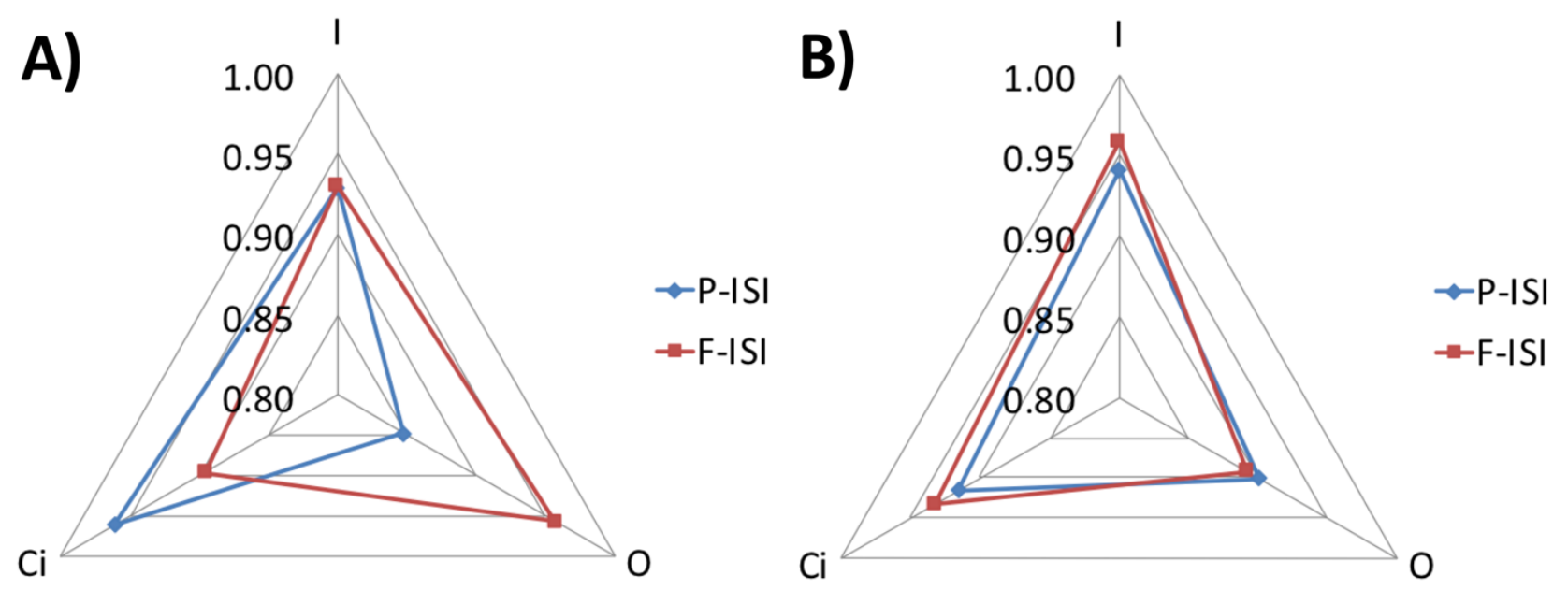

Figure 15.4. Innovation strategy index models. Past and the future timeframe innovation strategies in RAL model of (a) CC1 and (b) CC2. (Own research.)

\subsubsection{Case Company 2}

The innovation strategy type based on the ISI model in the past timeframe was inside-out OI strategy determined by the individual values of the different strategy types. The ISI value for inside-out OI strategy was moderately above the AVG value of other innovation strategy types. Based on the values determined for the future timeframe, the innovation strategy type was inside-out OI strategy, respectively. The values for this strategy type were the highest and sufficiently above the AVG value of the other innovation strategy type values as well (Table 15.1). The order of the different innovation strategy types based on their individual values in the case of CC2 was entirely different compared to the $\mathrm{CC} 1$. In the $\mathrm{CC} 2$, the order of the innovation strategy types in the past 
timeframe was inside-out>coupled>closed innovation>outside-in, and for the future timeframe inside-out >coupled>closed innovation > outside-in, respectively.

The value for coupled OI strategy type appeared to be relatively high as well in the past timeframe scenario. The SD of all the innovation strategy value of 0.0172 , which is marginally above the predetermined threshold used in this study, indicates that there is some variation between the innovation strategy types in the past timeframe. However, the CV-\% of $1.86 \%$ supports the coupled Ol strategy as it implies that the dispersion around the innovation strategy values is low. Correspondingly, in the future timeframe, the SD for the innovation strategy types was 0.0289, which is higher compared to the past timeframe scenario and significantly above the predetermined threshold of 0.015 . This supports the higher variation between the innovation strategy types in comparison with the other Ol strategy types obtained from the past timeframe. Furthermore, the CV-\% in the future timeframe was $3.10 \%$, which was also higher in comparison with the past timeframe scenario and, therefore, supports the inside-out OI strategy type for the future timeframe even further.

In the past timeframe, the ISI model results correlated moderately with priority weight values but did not correlate in the future timeframe (Figure 15.5). In the past timeframe, the highest value in the innovation strategy was in the inside-out OI strategy in both the ISI and the priority weight model. Correspondingly, in the future timeframe, the highest value of the innovation strategy types was in the inside-out OI strategy in the ISI model and outside-in OI strategy in the priority weight model respectively. According to the triangle area, the total innovation potential was 1.0978 in the past timeframe and 1.1182 in the future timeframe, respectively. As a result, the innovation potential is expected to grow $1.19 \%$ from the past innovation experience to the future innovation expectations. 
A)

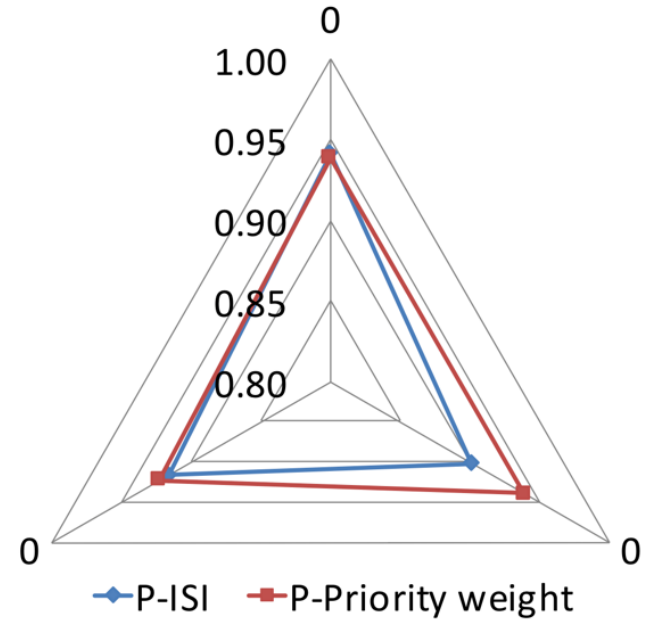

B)

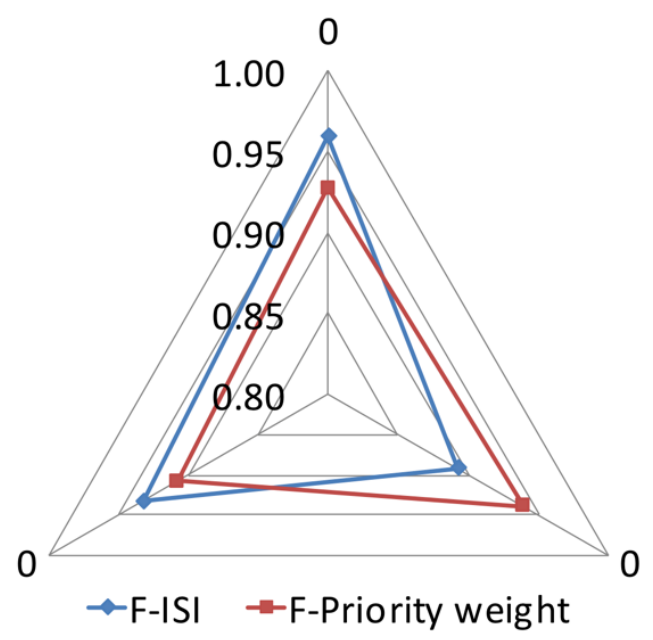

Figure 15.5. Innovation strategy index and priority weight comparison in CC2. RAL model (a) in the past timeframe and (b) in the future timeframe. (Own research.)

Based on the WMT, the empirical experience of the company's innovation strategy has been controversial. Majority of the answers obtained through interviews demonstrate the coupled innovation strategy in both the past and the future time- frame scenarios (Figure 15.4b). Nonetheless, both closed innovation and inside-out Ol strategies were mentioned as well. The logical explanation for the coupled OI strategy is that the three inside-out, outside-in, and coupled Ol strategies are all in place at the CC2. According to the company, its strategy includes acquiring other companies and external technologies. To conduct this, they have dedicated business development department and established channels to seek potential targets. The company also uses crowdsourcing to support their idea gathering process along with strategic co-operations and alliances with SMEs. In the past, they have also sold part of their operations which they see that do not fit into their future vision of the business. On the other hand, the company has a separate model of funding for the ideas that do not currently fit under any existing business development projects. Because the CC2 operates on a relatively wide area of innovation environment, it is harder to determine the effective innovation strategy for the company using the ISI model. Anyway, according to the WMT results obtained by interviewing the person in top management of the Finnish subsidiary, the ISI model and the pattern of both the past and the future RAL model figures cannot be ignored either (Figure 15.4b). Based on this, it can be determined that the past experience and the future expectations of the company are in line with the innovation strategy derived from the past and the future timeframe ISI models. 


\subsection{Discussion}

In this chapter, we demonstrated that the ISI model derived from MSI can be used for assessment of companies' innovation strategy, as both timeframe ISI models correlated in both case companies with the WMT obtained by interviewing the top management. However, the ICR has a significant impact on the reliability of the results. Although in this research the predetermined baseline of the ICR was set to 0.30 , it was observed with the MSI model that the results were more credible when the ICR was below 0.1. This can be especially confirmed by the case of CC2, where the ICR was 0.156 in the past timeframe and 0.111 in the future timeframe, respectively. Based on the results, the outside-in and coupled Ol strategy plays an important role in the case of companies' future scenarios, which has also been recognized in other studies concerning OI (Lichtenthaler, Hoegl \& Muethel, 2011). According to Lichtenthaler et al. (2011), the inside-out Ol strategy is very often impeded by "not-sold-here" syndrome by the companies, and therefore, the outside-in and coupled $\mathrm{OI}$ is favored. Although in knowledge-intensive industries, there is a demand for both in-licensing and out-licensing business models, the inside-out Ol strategy still plays a minor role compared to the outside-in Ol strategy (Gassmann \& Enkel, 2004).

The limitation of the AHP method is, however, that has been experienced to be too laborious and cumbersome due to the ICR, which needs to be taken into account. In order to harness it in companies, it needs to be connected to the enterprise resource planning (ERP) systems or financial reporting system, e.g., income statement or balance sheet. This integration would deploy the Big Data of the company and provide the raw information to be used in the analytics of the company's innovation status. Only then the information generated with this model could also be used as part of BSCs in a companies' innovation management (Campos, Sharma, Jantunen, Baglee \& Fumagalli, 2017). However, this integration needs to be implemented individually into separate companies, as the cost centers in the income statement vary significantly between different industries and business entities.

\subsection{Conclusion}

According to the results, the ISI model correlated with the past and future innovation strategy status and projections of the case companies (RQ3). Therefore, the proposed model will help companies to maintain their competitive advantage in global turbulent business environment (RQ1). However, the analysis of coupled Ol strategy is problematic due to its nature, which includes both types of 
outside-in and inside-out OI strategies. Therefore, the determination of coupled Ol strategy includes other factors as well in addition to the ISI values derived from the AHP questionnaire, such as the shape of the triangle which is influenced by the AVG values of all the innovation strategy values, SD, and CV-\%. However, lower ICR increases the reliability of the ISI values significantly in the case of coupled OI strategy as well. The ICR values were below 0.30 in all cases of the case companies. This concludes that the answers derived from this study are reliable and support that the results can be used in the decision-making process (Takala et al., 2013).

The $\Delta \mathrm{A}$ of the past experience to the future expectation gives valid information about the development of the total innovation potential of the company. However, the deeper function of this parameter was left out of scope of this study.

Although the AHP part of the method was experienced laborious to use when considering ICR, the value of the model in terms of managerial implications comes from the quantitative analysis of the current and future innovation strategy of the companies (RQ2). Despite this, in the future research, the proposed model should be validated and verified with other industries as well and not only with knowledge-intensive biotechnology and IVD industries. Additionally, more thorough connection to BSC should be investigated either through integration of the financial statements or ERP system of the company. 


\section{References}

Ahn, J. M., Ju, Y., Moon, T. H., Minshall, T., Probert, D., Sohn, S. Y., \& Mortara, L. (2016). Beyond absorptive capacity in open innovation process: The relationships between openness, capacities and firm performance. Technology Analysis \& Strategic Management, 28(9), 1009-1028.

Alyass, A., Turcotte, M., \& Meyre, D. (2015). From big data analysis to personalized medicine for all: Challenges and opportunities. BMC Medical Genomics, 8(33). doi:10.1186/s12920-015-0108-y.

Bogers, M., Chesbrough, H., \& Moedas, C. (2018). Open innovation: Research, practices, and policies. California Management Review, 60(2), 5-16.

Bower, J., \& Christensen, C. (1995). Disruptive technologies: Catching the wave. Long Range Planning, 28(2), 155.

Brem, A., Nylund, P. A., \& Hitchen, E. L. (2017). Open innovation and intellectual prop- erty rights: How do SMEs benefit from patents, industrial designs, trademarks and copyrights? Management Decision, 55(6), 1285-1306.

Campos, J., Sharma, P., Jantunen, E., Baglee, D. \& Fumagalli, L. (2017). Business perfor- mance measurements in asset management with the support of big data technologies. Management Systems in Production Engineering, 25(1), 143-149.

Cegarra-Navarro, J. G., Reverte, C., Gómez-Melero, E., \& Wensley, A. K. P. (2016). Linking social and economic responsibilities with financial performance: The role of innovation. European Management Journal, 34(5), 530-539.

Cheng, C. C. J., \& Huizingh, E. K. R. E. (2014). When is open innovation beneficial? The role of strategic orientation. Journal of Product Innovation Management, 31, 1235-1253. doi:10.1111/jpim.12148.

Chesbrough, H. (2003a). Open Innovation - The New Imperative for Creating and Profiting from Technology (pp. 30-53). Boston, MA: Harward Business School Press. 
Chesbrough, H. W. (2003b). The era of open innovation. MIT Sloan Management Review, 44(3), 3541.

Colombo, M. G., \& Garrone, P. (2006). The impact of M\&A on innovation: Empirical results. In: B. Cassiman \& M. Colombo (Eds.), Mergers and Acquisitions: The Innovation Impact (1st ed., pp. 104133). Cheltenham: Edward Elgar Publishing.

Daft, R. L., Murphy, J., \& Willmott, H. (2010). Organization theory and design: Cengage learning. In: Organization Theory and Design, R. L. Daft. (Ed.) 10th Edition. Mason, OH: Cengage Learning.

Dasgupta. (2013). Big Data: The Future is in Analytics. https://www.geospatialworld.net/ article/bigdata-the-future-is-in-analytics/. (Accessed September 18 2019).

Dziallas, M., \& Blind, K. (2019). Innovation indicators throughout the innovation pro- cess: An extensive literature analysis. Technovation, 80-81, 3-29. doi: 10.1016/j. technovation.2018.05.005.

Gassman, O. \& Enkel, E. (2004). Towards a Theory of Open Innovation: Three Core Process Archetypes. R\&D Management Conference. Lisbon: RADMA.

Gobble, M. M. (2013). Big data: The next big thing in innovation. Research Technology Management, 56(1), 64-66. doi:10.5437/08956308X5601005.

Gunday, G., Ulusoy, G., Kilic, K., \& Alpkan, L. (2011). Effects of innovation types on firm performance. International Journal of Production Economics, 133(2), 662-676. doi: 10.1016/j.ijpe.2011.05.014.

Heimo, T. (2019). Open Innovation in High-Technolog y Companies: Case Study of Biotechnology and Pharmaceutical Companies. Vaasa: University of Vaasa.

Karlsson, C., \& Tavassoli, S. (2016). Innovation strategies of firms: What strategies and why? Journal of Technology Transfer, 41(6), 1483-1506. doi:10.1007/s10961-015-9453-4. 
Lichtenthaler, U., Hoegl, M. \& Muethel, M. (2011). Is your company ready for open inno- vation? MIT Sloan Management Review, 53(1), 45-48.

Liu, Y., \& Takala, J. (2009). Modelling and evaluation of operational competitiveness of manufacturing enterprises. Kvalita Inovácia Prospeira, 13(2), 1-19.

Manyika, J., Chui, M., Brown, B., Bughin, J., Dobbs, R., Roxburgh, C., \& Byers, A. H. (2011). Big Data: The Next Frontier for Innovation, Competition, and Productivity. New York: McKinsey Global Institute. https://www.mckinsey.com/ /media/McKinsey/ Business\%20Functions/McKinsey\%20Digital/Our\%20Insights/Big\%20data\%20 The\%20next\%20frontier\%20for\%20innovation/MGI_big_data_full_report.ashx/ (Accessed September 12, 2019).

Mayer-Schönberger, V., \& Cukier, K. (2013). Big Data: A Revolution That Will Transform How We Live, Work, and Think. Boston, MA: Houghton Mifflin Harcourt.

Mohan, M., Voss, K. E., \& Jiménez, F. R. (2017). Managerial disposition and front- end innovation success. Journal of Business Research, 70, 193-201. doi:10.1016/j. jbusres.2016.08.019.

Najjar, M. S., \& Kettinger, W. J. (2013). Data monetization: Lessons from a retailer's jour- ney. MIS Quarterly Executive, 12(4), 213-225.

Pecchia, L., Bath, P. A., Pendleton, N., \& Bracale, M. (2011). Analytic hierarchy process (AHP) for examining healthcare professionals' assessments of risk factors: The relative importance of risk factors for falls in community-dwelling older people. Methods of Information in Medicine, 50(5), 435-444. doi:10.3414/ME10-01-0028.

Racherla, U. S., Huang, K. G., \& Liu, K. (2016). Innovation and IPRs in China and India. In China-EU Law Series (Vol. 4). Singapore: Springer. doi:10.1007/978-981-10-0406-3.

Ranta, J. M., \& Takala, J. (2007). A holistic method for finding out critical features of industry maintenance services. International Journal of Services and Standards, 3(3), 
312-325. doi:10.1504/IJSS.2007.013752.

Takala, J., Shylina, D., Forss, T. \& Malmi, J. (2013). Study on resource allocations for sustainable competitive advantage. Management and Production Engineering Review, $4(3), 65-75$.

Vanani, I. R., \& Kheiri, M. S. (2018). Big data and its role in facilitating the visualization of financial analytics. In R. Segall \& J. Cook (Eds.), Handbook of Research on Big Data Storage and Visualization Techniques (1st ed., pp. 704-722). Hershey, PA: IGI Global.

Wind, Y. \& Saaty, T. (1980). Marketing applications of the analytic hierarchy process. Management science, 26(7), 641-658.

Yang, C., Huang, Q., Li, Z., Liu, K., \& Hu, F. (2017). Big data and cloud computing: Innovation opportunities and challenges. International Journal of Digital Earth, 10(1), 13-53. doi:10.1080/17538947.2016.1239771. 